\title{
A Study on the Current Agricultural Land Transfer Information Platform
}

\author{
Xin $\mathrm{Chu}^{1, \mathrm{a}}$ \\ ${ }^{1}$ Wuhan Donghu University, Wuhan City, Hubei Province, 430212, China \\ aemail:
}

Keywords:Agricultural land transfer; Informatization; Driving force; Model; Service system

\begin{abstract}
Under the promotion of relevant policies in the country, China's agricultural land transfer appears to accelerating development situation. Along with the rural information infrastructure gradually improved with increasingly using of big data, cloud computing technology in the field of agriculture, the Internet and e-commerce began to go to rural areas. These factors are speeding up the process of development of land transfer information. The establishment of e-commerce platform for agricultural land transfer based on Internet technology is not only a form of innovation, but also a useful exploration of the informatization of agricultural land transfer in China. However, the moderate scale management of agricultural land transfer is still existing restraining factor, such as system and personnel factors. Therefore, on the basis of successful experience of the national agricultural land transfer, we should formulate the corresponding policy of agricultural land transfer according to the needs of economic and social development. Based on the author's research and practical experience, this paper first analyzed the driving force of China's agricultural land transfer informatization, and then discussed the model of agricultural land transfer in China, and finally put forward the strategy of establishing agricultural land transfer service platform.
\end{abstract}

\section{Introduction}

The Chinese government is committed to long-term stability in the premise of land rights in order to increase agricultural output after improving factor input. However, with the marginal utility of factor inputs continue to decline, inefficient agricultural subsidies, high pollution, food safety and other issues become more serious caused by high investment. At present, the domestic agricultural labor force has been reduced to 240 million people with most of unprofessional farmers. At this stage, the orderly promotion of agricultural land transfer promotes the scale of agricultural land management, which is as an improvement of the production efficiency of the agricultural industry. This has become the best way to realize agricultural modernization and sustainable development.

\section{The Driving Force of Agricultural Land Transfer Informatization in China}

Policy has gradually shifted to agricultural informatization in recent years. Since the reform and opening up, the Chinese government has been committed to the construction and development of agricultural information. In 2011, after the State Council issued the National Agricultural and Rural Informatization Development of 12th Five-Year Plan, the state has increased support for the development of agricultural information. Especially since the beginning of 2015 and with the "Internet plus" becoming the national strategy, the central government attaches great importance to the construction of agricultural informatization again. With the introduction of a series of support policies, the policy environment for the development of agricultural informatization has been continuously optimized. 
Technical conditions for the development of agricultural information has gradually become mature. First, rural basic information equipment has basically equipped. After years of construction, China's agricultural and rural information infrastructure has improved, and fiber optic broadband to the village with rural broadband project are in full worked. At the same time, the Ministry of agriculture has constructed nearly 40 information collection channels in the national agricultural system with deployed more than 800 information collection points, and formed more than 60 industry databases. The province, city and county agriculture website groups are basically completed. The agricultural departments at all levels have initially set up agricultural information service platform to provide information, science and technology, market, policy and other information for agricultural practitioners. All of these fully show that the resources and channels for the development of agricultural informatization in China are already available.

Second, the Internet and e-commerce began to go deeper into the countryside. The concept of e-commerce has been widely accepted by agricultural practitioners. The research data of Ali research institute show that the sales of agricultural products on the Taobao platform increase year by year, maintaining a growth rate of $100 \%$ per year. The new agricultural Internet business models such as "land allotment" also continues to be developed, and the Internet thinking began to enter the rural areas, focusing on the large agricultural market, which was greatly promoted the development of agricultural information.

Third, big data, cloud computing, remote sensing and other emerging technologies began to be applied in depth. Although the overall situation of agricultural production in our country is still in a relatively backward state, and it must be seen that agriculture is not the traditional technology for desert cognition. In fact, data analysis technology, cloud computing and remote sensing technologies have been explored in agriculture for several years. With the maturity of relevant technical means and the rich application, the depth and breadth of its technology application has been greatly improved, and the future development is more worthy of expectation.

\section{Analysis of Agricultural Land Transfer Mode}

Agricultural land exchange. The agricultural land exchange refers to the simple exchange of the contractual rights of farmers in the rural collective economic organizations for the convenience of farming and their own needs. This is the only way to promote scale, industrialization and intensive management of rural areas. Thirty years ago, the rural land contract responsibility system was implemented in China, and the peasants were divided into agricultural land. But because of a large size of farmland, farmland is divided into departments and regions. All the ills of the left division of farmland seriously restrict the development of productivity and increase the yield. The question of how to make the land to achieve scale and intensive management is what we concerned. So such primitive way of trading enters the field of vision.

Lease of farmland. Driven by the market and guided by the government, farmers lease their right of management on agricultural land to large family, owner or enterprise legal person,etc. The time limit for rent and the mode of payment for rent shall be agreed by both parties. The tenant can get a certain period of farmland management right, and the lessor can obtain land rent according to the annual or in the form of money. Among them, there are lots of tenants, such as a large tenant and leasing companies. The key problem is how to guarantee the legitimacy and make both feel unworried.

The shares of agricultural land. Shares, also known as "stock land system" or joint stock operation, which refers to the establishment of farmers' cooperatives or joint-stock companies on the basis of insisting on the willingness of the contracted households to share the Contractual Land 
Management Rights. The two-way choice of rural land management in the process of rural land share will be implemented (After the rural land shares entering the cooperatives, farmers can continue to participate in agricultural land management, or do not participate in agricultural land management). Farmers with land contract right can have cooperative equity and dividends. The biggest advantage of this form is clear property rights and direct interests. Moreover, farmers' contractual right of farmland has been determined for a long time as a form of value. Further, farmers are not only the participants of cooperatives, but also the owners of interests. It is a new breakthrough in the current agricultural land transfer mechanism.

Residential housing. Let's take Chongqing as an example. After approved as a national urban and rural comprehensive reform pilot area last year, Chongqing took the lead in the field of land reform in the bold exploration, and created the land transfer mode of Jiulongpo. This is a mode of homestead for housing with contracted for social security. That is to say, if farmers give up the rural homestead, homestead will be replaced by city development land, and farmers will get a house in the city. Farmers abandon the right of contracted management of rural land and enjoy urban social security, so that to establish a unified public service system in urban and rural areas.

Joint stock partnership. Ningyang County of Shandong Province in China explores the new mechanism of the transfer of agricultural land contractual management right, and establishes a "share plus cooperation" mode of agricultural transfer and distribution. This mode is a cooperative which is established by farmers with the right of land management. In accordance with the principle of "voluntary participation of the public, farmland shares, intensive management, profit sharing, protection of interests", the village committee guides farmers to share the land contractual management rights. Cooperative manage the farmland in accordance with the principle of democracy, which is not managed by farmer again. Cooperatives affiliated leading enterprises to make production and management.

\section{Establish Countermeasures of Agricultural Land Transfer Service Platform}

Perfect information exchange mechanism. Whether the information exchange mechanism is sound or effective, it is directly related to the quality and efficiency of land transfer. At present, due to the unfavourable farmers' agricultural land transfer information channel, small space of farmland transfer, limited scope of farmland transfer and high cost, the quality is not satisfactory. Government departments should strengthen the construction of information mechanism of agricultural land transfer to adapt to the requirements of rural development, focusing on the need of farmers. Moreover, they should positively provide guidance and information services for agricultural land transfer. Further, the government should adapt to the requirements of the information society, and improve the agricultural land transfer information collection, processing, storage and transmission mode, so that to improve the level of information and electronic. All localities should establish regional land transfer information service center, and established the county, township and village three level of farmland transfer market service system by the County Rural Land Transfer Service Center, Center Township and village land transfer service land transfer service stations. On this basis, they will gradually establish a nationwide information platform including the land transfer, the network communication platform and decision support platform, the transfer of farmland information management system.

Establishing policy consultation mechanism. The policy of agricultural land transfer is strong and directly related to the livelihood of farmers. We must make scientific,and democratic decisions. To this end, we need to establish a policy consulting mechanism to better play the role of policy consulting in the transfer of farmland. The first is to pay attention to the top-level design and 
respect the masses first combination. Agricultural land transfer reform and policy making need top-level design, and can not be divorced from the masses of practice, exploration and creation. We should be good at summing up the characteristics, valuable new practices and new experiences from the practice of agricultural land transfer, and realize the organic combination of top-level design of policy and the initiative of the masses. In addition, the agricultural land transfer involves the farmers' employment, social security, education, health, urban and rural development and other aspects of the policy, which need to know the land transfer system of agricultural land transfer and jump out of views, so that to make extensive collection and adoption of reasonable proposals, and ensure scientific decision-making of rural land. The second is to construct policy consultation system. We need to establish an expert consultation institution for farmland transfer, and carry out a diversified and socialized policy of farmland transfer; we need to implement the systematic policy consultation to ensure the speciality of the decision-making of agricultural land transfer; we need to improve the supporting policies and systems to form a policy consultation system of agricultural land transfer, which is based on the main policy system and supported by the information, consultation and supervision subsystem.

Perfect price evaluation mechanism. The price evaluation of agricultural land transfer is the core of establishing and perfecting the agricultural land transfer market, and the key to realize the reasonable and equitable distribution of land revenue in the country, village collective, outflow, inflow and management. Therefore, it is necessary to improve the price evaluation mechanism of rural land transfer. The first is to construct scientific farmland grading system. The rural land has differences in grade, fertility and location, which not only has the absolute rent,but also has land tax. The circulation of agricultural land information database should be established. We have to grade the farmland by convection, and formulate benchmark prices, including the differential income of farmland, regional differences, infrastructure conditions and other factors. The second is to establish and improve the transfer of agricultural land assets evaluation institutions. The introduction of third party agricultural land assessment agencies and assessors make assess on the price of the convective transaction. Third is to develop and improve the transfer of agricultural land evaluation index system. We want to set up the actual price system with high accuracy of the transfer of agricultural land price evaluation method and the minimum protection, so that to ensure the transfer of agricultural land valuation rules. Fourth is to establish and improve the agricultural land transfer evaluation price information collection, processing and public release system. Transparency of information is the premise of market mechanism to play its role. We should establish the register of agricultural land price information, including the transfer of agricultural land benchmark prices, the evaluation of prices and transaction prices, etc. We should reflect the transfer price change trend, and timely released to the public through the electronic information network. The fifth is to establish a unified nationwide dynamic monitoring system of farmland price, and improve the evaluation mechanism of farmland prices.

\section{Acknowledgement}

This work was supported by the grants from Youth Foudation WuHan Donghu University

\section{References}

[1] Zhu Jiarong, Zhu Zhaozhi. Path Selection of Rural Land Transfer Based on Platform Construction[J]. Theoretical Observation, 2014, (06): 107-108.

[2] Wang Jianming, Fan Wenzhong. The Exploration and Suggestion of Rural Land Transfer 
Informatization Management and Service Mechanism in Huangzhong County[J]. Rural Economy and Science and Technology, 2016, (05): 230-231.

[3] Zhang Yabin. The Problems and Countermeasures of Rural Collective Land Management Rights Transfer[J]. Henan Agriculture, 2016, (08):

[4] Hu Laihua. Content and Requirement of Establishing Rural Land Transfer Information Database[J]. Anhui Agricultural Science Bulletin (Half Monthly), 2011, (21): 3+13.

[5] Li Guoying. Rethinking on the Informatization of Rural Land Transfer in China[J]. China Land and Resources Economy, 2015, (09): 32-36.

[6] Zhang Simei. Transfer of Rural Land in China From the Perspective of Population Structure Change[J]. Economic Geography, 2014 (08): 131-136.

[7] Liu Yan. Discussion on the Legalization of Property Right System in Rural Land Transfer[J]. Chinese Journal of Agricultural Sciences, 2014, (11): 45-50. 